\title{
BMJ Open Perspectives of mild asthma patients on maintenance versus as-needed preventer treatment regimens: a qualitative study
}

\author{
Juliet Foster (D) , ${ }^{1}$ Richard Beasley (D) , ${ }^{2}$ Irene Braithwaite (D) , ${ }^{2}$ Tim Harrison (D) , ${ }^{3}$ \\ Mark Holliday (D) , ${ }^{2}$ lan Pavord (D) , ${ }^{4}$ Helen Reddel (D) ${ }^{1}$
}

To cite: Foster J, Beasley R, Braithwaite I, et al. Perspectives of mild asthma patients on maintenance versus as-needed preventer treatment regimens: a qualitative study. BMJ Open 2022;12:e48537. doi:10.1136/ bmjopen-2020-048537

- Prepublication history and additional supplemental material for this paper are available online. To view these files, please visit the journal online (http://dx.doi.org/10.1136/ bmjopen-2020-048537).

Received 05 January 2021 Accepted 15 September 2021

\section{Check for updates}

(c) Author(s) (or their employer(s)) 2022. Re-use permitted under CC BY-NC. No commercial re-use. See rights and permissions. Published by BMJ.

${ }^{1}$ The Woolcock Institute of Medical Research and The University of Sydney, Sydney, New South Wales, Australia ${ }^{2}$ Medical Research Institute of New Zealand, Wellington, New Zealand

${ }^{3}$ Nottingham Respiratory Medicine Unit and NIHR Biomedical Research Centre, University of Nottingham, Nottingham, UK

${ }^{4}$ Respiratory Medicine Unit and Oxford Respiratory NIHR Biomedical Research Centre, University of Oxford, $0 x$ ford, UK

Correspondence to

Prof Helen Reddel;

helen.reddel@sydney.edu.au

\section{ABSTRACT}

Objectives As-needed low-dose combination budesonide-formoterol is recommended by asthma guidelines in many countries as an alternative to maintenance inhaled corticosteroids (ICS) for treatment of mild asthma, but there are few data on patient attitudes toward these regimens. This study explored the comparative implementation experiences and future treatment preferences of mild asthma patients who had experienced these two treatment regimens.

Setting A subgroup of adults randomised to maintenance ICS or as-needed ICS-formoterol in a multinational, 52-week open-label randomised controlled trial (NovelSTART) in mild asthma patients were interviewed to explore their motivations for treatment use during the study and their preferences for future treatment

Participants Semistructured interviews were conducted with 74 participants (Maintenance group: $n=39$, As-needed group $n=35$, mean age 38 (range 19-69)) and thematically analysed from transcribed audiorecordings.

Results Emergent themes from analysis comprised: 'How much my asthma affects me' (how their asthma's impact affected their self-management motivation); 'What I know about asthma' (limited knowledge impeded appropriate self-management decision making); 'How much effort this treatment regimen involves for me' (treatment complexity and/or difficulty establishing a medication routine impeded implementation, particularly in the Maintenance group); and 'My beliefs about the benefits and risks of this treatment' (patients who considered their treatment as ineffective, eg, limited difference in symptoms relative to salbutamol (both groups) or slower onset of relief (Asneeded group) had poor motivation to use the treatment). Due to the simplicity of the as-needed combination strategy, this was the preferred future regimen, even by patients who had not yet tried it.

Conclusions Key patient perspectives on the implementation of preventer treatments for mild asthma included factors relating to perceived asthma burden, disease knowledge, treatment complexity and treatment usefulness or safety. The as-needed budesonide-formoterol regimen was preferred to maintenance ICS treatment in mild asthma though patient education is urgently needed to address implementation motivation.

Trial registration number ACTRN12615000999538.

\section{Strengths and limitations of this study}

- Qualitative research was prospectively integrated into the design of the pragmatic clinical trial, in order to obtain patient perspectives about new and existing treatment options for patients with mild asthma.

- The use of qualitative methods, in a large interview sample size, is a major strength of this study allowing a more patient-centred understanding of inhaled corticosteroid regimen preference than those described from quantitative methodology in the few previous studies.

- The generalisability of the results to patients in the general community may be limited since interviewees were participants in a 12-month long NoveISTART randomised controlled trial (RCT), most had postschool education, and none had very recently-diagnosed asthma and/or were new to asthma medications.

- Despite concerted efforts, we were unable to interview patients who had withdrawn from the NoveISTART RCT.

\section{INTRODUCTION}

In many countries, as-needed low-dose combination budesonide-formoterol is now recommended as an alternative to maintenance low-dose inhaled corticosteroids (ICS) for treatment of mild asthma. These guidelines, following on from 2019 Global Initiative for Asthma recommendations, ${ }^{12}$ are based on randomised controlled trial (RCT) evidence in almost 10000 patients showing that as-needed ICS-formoterol outperforms as-needed short-acting beta ${ }_{2}$ agonist (SABA) alone ${ }^{34}$ and performs similarly or better than twice daily maintenance ICS plus as-needed SABA, ${ }^{3-6}$ for exacerbation prevention in mild asthma. It achieves this without clinically important differences in symptom control or lung function, ${ }^{3-6}$ and at a lower ICS $\operatorname{dose}^{3-6}$ relative to ICS maintenance. ${ }^{7}$

Knowledge of patient attitudes is crucial for optimising their treatment 
implementation, particularly when new treatments are introduced. Despite growing data about patient perspectives in moderate to severe asthma, there is still limited information on attitudes toward using ICScontaining treatment in mild asthma, although it is known that patients using a SABA-alone regimen may find it difficult to justify, or may have concerns about, adding a corticosteroid medication if they consider their disease insignificant or unproblematic. ${ }^{89}$

A qualitative substudy ('NovelQ') was incorporated into the 12-month NovelSTART RCT $^{3}$ to understand mild asthma patients' attitudes toward two different ICS-containing regimens: maintenance twice daily budesonide $(200 \mu \mathrm{g})$ plus as-needed salbutamol, or as-needed combination budesonide-formoterol $(200 / 6 \mu \mathrm{g})$. We have previously reported that patients randomised to as-needed combination therapy found it to be an acceptable reliever therapy compatible with established reliever-taking habits, but they identified the importance of health professional support with transition to this treatment. ${ }^{10}$

The present paper explores the comparative implementation experiences and future treatment preferences of mild asthma patients randomised to either maintenance twice daily budesonide plus as-needed salbutamol or as-needed budesonide-formoterol, who had used SABA-only treatment for $\geq 3$ months before study enrolment.

\section{MATERIAL AND METHODS}

We reported our results following the Consolidated Criteria for Reporting Qualitative Research guidelines. ${ }^{11}$ See online supplemental material for detailed methods.

\section{Patient and public involvement}

There was no patient or public involvement in the study development or design.

\section{Participants}

Adults enrolled in a multinational, 52-week open-label RCT had doctor-diagnosed mild asthma with no recent asthma hospitalisations and used SABA as their sole asthma therapy in the previous 3 months. Full details are reported elsewhere. ${ }^{312}$

Of NovelSTART RCT patients randomised to maintenance twice-daily budesonide $200 \mu \mathrm{g}$ by Turbuhaler plus as-needed salbutamol by pMDI ('Maintenance' regimen), or as-needed budesonide-formoterol $200 / 6 \mu \mathrm{g}$ by Turbuhaler ('As-needed combination' regimen), a subsample was selected for the NOVELQ qualitative study by purposive sampling to provide diversity by age and sex. Each patient in the sub-sample was provided with NOVELQ study information and invited, by letter, for one telephone interview occurring after 10 months participation in the RCT. Any invited participant who indicated their interest by contacting the study coordinator was scheduled for interview after providing written informed consent.

\section{Study design and interviews}

This qualitative study involved a single semistructured, in-depth interview $\geq 10$ months into the study with each NovelQ patient randomised to receive either the 'Maintenance' (twice daily low dose ICS), or 'As-needed combination' (as-needed low dose budesonideformoterol) regimen. The interviews aimed to investigate patients' motivations for implementing these regimen options (both before and during the study) and their preferences regarding future mild asthma treatment. All interviews were conducted by telephone and audiorecorded. Each participant was informed that their interview data would be kept confidential and that the interviewer (JF) had no involvement in the NovelSTART RCT.

Our interview guide (online supplemental material) incorporated semistructured questions on mild asthma patients': (1) experiences with their allocated RCT treatment (eg, implementation or treatment concerns and/or changes in asthma symptoms); (2) preferences regarding future reliever and preventer treatment options for mild asthma and (3) life with mild asthma, if this arose during the interview, to provide context to the experiences and preferences described. Using an iterative process, any new theme emerging from a prior interview was followed up in subsequent patients' interviews.

\section{Analysis}

Interviews were transcribed verbatim then anonymised. Interviews and analysis were conducted by coauthor JF, using thematic content analysis, ${ }^{13}$ followed by descriptive then inductive pattern coding and finally synthesis into the themes which emerged from the data. ${ }^{14} \mathrm{An}$ audit trail was created to optimise analysis rigour. ${ }^{15}$ Full details are reported in online supplemental material and elsewhere. ${ }^{10}$

\section{RESULTS}

Of 108 participants invited, 39 of $50(78 \%)$ in the 'Maintenance' group and 35 of 58 (60\%) 'As-needed combination' group participated in an interview (online supplemental material). The 74 participants ('Maintenance' group: mean age 38 (range 19-69), Asthma Control Questionnaire (ACQ) 5-item score mean \pm SD 1.12 \pm 0.71 ; 'As-needed combination' group: mean age 44 (18-74), ACQ-5 1.09 \pm 0.55 ; table 1) were interviewed for an average of 40 (range 18-62) min. Sixty-four per cent of the 'Maintenance' group, and $71 \%$ of the 'As-needed combination' group, reported ever having used an ICS-containing controller prior to participation in, but not within 3 months of enrolling in NovelSTART. 
Table 1 Demographics and baseline characteristics

\begin{tabular}{|c|c|c|}
\hline Interviewee baseline characteristics & $\begin{array}{l}\text { Maintenance twice daily ICS plus } \\
\text { as-needed salbutamol } \\
\mathrm{N}=39\end{array}$ & $\begin{array}{l}\text { As-needed budesonide- } \\
\text { formoterol } \\
\mathrm{N}=35\end{array}$ \\
\hline Female & $44 \%$ & $66 \%$ \\
\hline Age, years (mean: range) & 37.7: 19.0-69.0 & 43.5: $18.7-74.4$ \\
\hline Ethnicity, caucasian/other & $79 \% / 21 \%$ & $75 \% / 25 \%$ \\
\hline $\begin{array}{l}\text { Highest level of education, high school/ } \\
\text { postsecondary education }\end{array}$ & $26 \% / 74 \%$ & $14 \% / 86 \%$ \\
\hline $\begin{array}{l}\text { Asthma Control Questionnaire 5-item score (range } \\
0-6)(\text { mean } \pm S D) \ddagger\end{array}$ & $1.12 \pm 0.71$ & $1.09 \pm 0.55$ \\
\hline $\mathrm{FEV}_{1} \%$ predicted (mean: range) & 93.1: $65-128$ & 88.5: $61-121$ \\
\hline$\geq 1$ Severe exacerbation in previous year* & $8 \%$ & $0 \%$ \\
\hline Ever prescribed inhaled corticosteroid $\dagger$ & $64 \%$ & $71 \%$ \\
\hline
\end{tabular}

Interviews were conducted on average 10.9 months ( $S D \pm 0.7$ ) ('Maintenance' group), 10.5 months ( $S D \pm 0.9)$ ('As-needed combination' group) after randomisation in the 12-month RCT.

*Definition of severe asthma exacerbation: a. The use of systemic corticosteroids for at least 3 days because of asthma, or b. Hospitalisation or ED visit because of asthma, requiring systemic corticosteroids ( $0 \%$ of interviewees had an ED visit for asthma in the 12 months prior to RCT visit 1).

†Patients were not permitted to have taken inhaled corticosteroid in the 3 months prior to enrolment. $\ddagger A C Q$ Score $\geq 1.5=$ poor symptom control.

ACQ, Asthma Control Questionnaire; ED, emergency department; FEV , forced expiratory volume in 1 second; RCT, randomised controlled trial.

Emergent themes from the analysis of interviews described the motivations for patients' regimen implementation decisions or behaviours. The themes comprised: 'How much my asthma affects me', 'What I know about asthma', 'How much effort this treatment regimen involves for me' and 'My beliefs about the benefits and risks of this treatment'. In the results reported below, themes emerged from both randomisation groups unless otherwise specified; some data from the 'As-needed combination' group have been reported elsewhere. ${ }^{10}$ Brief interview quotations are presented below with a unique patient ID and randomisation group; see expanded quotes in the following tables.

\section{Motivations for treatment implementation in mild asthma}

The motivations common to patients who had received either RCT regimen were represented by the themes 'How much my asthma affects me' and 'What I know about asthma'.

How much my asthma affects me (theme 1)

Most individuals described predominantly unproblematic asthma which they felt required only minimal active treatment:

I don't manage my asthma very actively. 'Cause like I don't need to... (ID98-Maint)

Indeed some did not consider their asthma in any way life-threatening:

I know [if] I want to go climbing a hill...I'm going to get some symptoms but that's really about it. I'm not disabled by it, and there's nothing life-threatening about it (ID97-As-needed)

One interviewee described their own, and their healthcare professionals', complacency around mild asthma:

Everyone is complacent. I mean me, my GP, the pharmacist and even my husband... Medical professionals don't treat mild asthma seriously. They think "You'll be right. Just take Ventolin". There's no follow up (ID96-Maint)

Interestingly, interviewees also described habituating to their asthma symptoms and/or having difficulty differentiating symptoms from other potential causes; this perhaps impacted their perceptions of the risks of mild asthma:

Yeah it's hard for me to decipher. I would also feel chest tightness anyways in amongst [anxiety] so I would definitely be confused whether it was asthma or if it was just something else... (ID50-Maint)

In contrast, some individuals described periods of uncontrolled asthma symptoms, or progressively worsening asthma control (prior to the study), that required closer and/or intermittent, management, for example,

I'd noticed now I'm in my 40s, [my asthma] seemed to be getting worse. I just seemed to be needing [my reliever] more...

(ID87-As-needed)

Despite the diversity of asthma experiences, interviewees rarely mentioned significant hindrances on their life due to mild asthma. The life limitations 
reported were predominantly associated with physical exertion, sometimes only during a respiratory illness. However, asthma did limit some interviewees' lifestyle choices in both regimen groups, though it was unclear the extent to which this influenced the patient's use of their RCT treatment.

Expanded quotes relating to theme 1 are found in table 2.

Table 2 How much my asthma affects me (theme 1)

RCT group* Quotation

\subsection{Perceiving unproblematic asthma which requires only minimal active care:}

Maintenance 'I don't manage my asthma very actively. 'Cause like I don't need to, 'cause it's mild... it's only really during high intensity exercise that I get (asthma) symptoms.'. (ID98)

As-needed 'It's been a long time since l've had really bad asthma. Yeah, a long, long time. [In recent years] I have combination [only] woken up in the night the odd time and taken Ventolin'. (ID27)

\subsection{Perceiving asthma as not life-threatening:}

Maintenance [I've had experiences when] it's now 7 o'clock at night and I can't see a GP [to get] me a damned inhaler, which is particularly frustrating... [but] I know I'll be fine through the night. I'll get through it. ...it's not something which I would find life-threatening.' (ID120)

\section{As-needed} combination

'It's a mild annoyance at the moment. I know [if] I want to go climbing a hill...I'm going to get some symptoms but that's really about it. I'm not disabled by it, and there's nothing life-threatening about it' (ID97)

\subsection{Complacency around mild asthma:}

Maintenance

'Everyone is complacent. I mean me, my GP, the pharmacist and even my husband, although he'll kill me for saying that ((laughs))... Medical professionals don't treat mild asthma seriously. They think 'You'll be right. Just take Ventolin". There's no follow up when you visit the GP [for reasons other than asthma]. They don't ask about your asthma...it's my health, my life. But [it's] the GP's job to oversee how your asthma's going.' (ID96)

\subsection{Habituating to asthma symptoms:}

Maintenance 'My husband reminds me like 'Why don't you] use the inhaler?' Probably I start making this ((makes sound)) like clearing my throat. I mean he can notice [my asthma symptoms] probably before me... I think I got used to them.' (ID65)

$\begin{array}{ll}\text { As-needed } & \text { 'I might be wheezy for a reason, and um, but I don't maybe notice it, and someone else will notice it... } \\ \text { combination } & \text { You just get used to it and you just cope, you, like, learn to cope with it and so you don't deal with it.'. } \\ & \text { (ID40) }\end{array}$

\subsection{Difficulty differentiating asthma symptoms from other potential causes:}

\begin{tabular}{|c|c|}
\hline Maintenance & $\begin{array}{l}\text { 'Yeah it's hard for me to decipher. I would also feel chest tightness anyways in amongst [anxiety] so I } \\
\text { would definitely be confused whether it was asthma or if it was just something else, um, [like] me just } \\
\text { hyperventilating.' (ID50) }\end{array}$ \\
\hline $\begin{array}{l}\text { As-needed } \\
\text { combination }\end{array}$ & $\begin{array}{l}\text { 'It is very hard [to decipher the cause] because if it's anxiety coming first and then you get the shortness } \\
\text { of breath, it makes the anxiety worse. But then if it's the shortness of breath first, because I had very bao } \\
\text { asthma as a kid... then the shortness of breath leads to even more anxiety cause you're freaking out, } \\
\text { you know, like a catch 22.' (ID26) }\end{array}$ \\
\hline \multicolumn{2}{|c|}{ 2.6 Experiencing uncontrolled asthma symptoms or progressively worsening control: } \\
\hline Maintenance & $\begin{array}{l}\text { 'Normally when I'm sick, if it's anything to do with my chest (e.g. a chest infection, or anything that } \\
\text { affects my breathing) my asthma gets really bad so I have to go on prednisone.' (ID11) }\end{array}$ \\
\hline $\begin{array}{l}\text { As-needed } \\
\text { combination }\end{array}$ & $\begin{array}{l}\text { 'I'd noticed now I'm in my 40s, [my asthma] seemed to be getting worse. I just seemed to be needing } \\
\text { [my reliever] more, um and I wasn't really sure [why]. There didn't seem to be rhyme or reason as well. It } \\
\text { wasn't seasonal. It was definitely worse if I was sick.' (ID87) }\end{array}$ \\
\hline
\end{tabular}

\subsection{Hindrances on life due to mild asthma:}

$\begin{array}{ll}\text { Maintenance } & \begin{array}{l}\text { 'I really make every effort that I'm not late for the bus that I don't have to run for it...I absolutely avoid } \\ \text { exercise... I've had a couple of times where it's been very scary.... so I'm just more careful now... } \\ \text { [instead] I garden'. (ID23) }\end{array} \\ \begin{array}{l}\text { As-needed } \\ \text { combination }\end{array} & \begin{array}{l}\text { 'Because colds would generally sort of settle on my chest and then exacerbate my asthma I'd find it } \\ \text { really dicult just to do simple things like getting up and down stairs.' (ID81) }\end{array}\end{array}$

${ }^{\star} \mathrm{RCT}$ allocation group of quoted interviewee.

$\mathrm{RCT}$, randomised controlled trial. 
What I know about asthma (theme 2)

Interviewees described limited knowledge about asthma and limited learning opportunities in primary care settings:

It depends on which GP you go to. Some of them you see for 5, 10 minutes max, and which is only just enough for them to look at you and go 'Yes this is what your problem is. Here's some drugs. Off you go'... (ID79-Maint)

Doubt about the credibility of their asthma diagnosis was also communicated by interviewees, often due to comparisons they made with sicker peers who had asthma:

I never really thought about [having] asthma um, because even in those moments it wasn't like really struggling for breath. And I had a friend who died ... from asthma, so I know what his struggles were like and obviously mine were nothing even remotely close to what he had. (ID63-Maint).

Further, limited asthma knowledge affected appropriate management, such as knowing when to seek healthcare:

There was that one night where I was coughing and coughing and I actually started getting concerned. I thought 'Well where is the point where I need to actually, you know, get help?'. (ID64-As-needed).

Expanded quotes relating to theme 2 are found in table 3 .

The motivations for treatment implementation that were more diverse between the two RCT treatment groups were represented by the themes: 'How much effort this treatment regimen involves for me' (theme 3) and 'My beliefs about the benefits and risks of this treatment' (theme 4).

How much effort this treatment regimen involves for me (theme 3) Patients taking the 'Maintenance' regimen reported difficulty comprehending two different treatment approaches in the same regimen:

I have to consciously think 'Right this inhaler needs to be used that way' [taken twice a day], as opposed to just having one [treatment approach] and thinking of one way of using it [take it as-needed]. (ID102-Maint)

The requirement for two different inhalers in the 'Maintenance' regimen prompted comparison of the inhalers;

Table 3 What I know about asthma (theme 2)

\section{RCT group Quotation}

\subsection{Asthma knowledge deficits:}

As-needed [In the past my GP explained] that [my preventer] needs to be taken over a long period of time because the combination medication builds up in your system. But at the same time I pointed out [to the GP] that I have such mild asthma and do I really need it. And he sort of 'ummed and ahhed' and said 'It's probably a borderline case'... [and] probably I decided that Ventolin was a borderline case and actually [I didn't] need the preventer at all ((laughs)) which may or may not have been what he meant, but that's how I interpreted it.' (ID117)

\begin{tabular}{|c|c|}
\hline $\begin{array}{l}\text { As-needed } \\
\text { combination }\end{array}$ & $\begin{array}{l}\text { "That was the turning point for me: that I had asthma and my child has asthma. That was [when I thought] I } \\
\text { need to know more [about asthma]. After [14 years after my asthma diagnosis],[I realised]'Ohhhh, I know what } \\
\text { it [asthma] is now' [after] reading Facebook stuff about Asthma Foundation, reading about the symptoms ...I'm } \\
\text { thinking 'Ohhhh these were the symptoms that I ignored'.' (ID118) }\end{array}$ \\
\hline Maintenance & $\begin{array}{l}\text { 'IIn the past] I don't think I understood when I was [first] given the [preventer] one, what I was supposed to } \\
\text { do with it or when. So I just carried on with the blue one...I didn't know whether it was supposed to be a } \\
\text { substitute or additional, and when I was supposed to use it. So, it was my own fault...I should've asked'. (ID76) }\end{array}$ \\
\hline $\begin{array}{l}\text { As-needed } \\
\text { combination }\end{array}$ & $\begin{array}{l}\text { 'My boyfriend gets wheezy symptoms and takes more medicines than just Ventolin whereas I don't, so I } \\
\text { thought 'I don't have asthma then because I don't wheeze'. I just cough at night time, or when I play hockey' } \\
\text { (ID118) }\end{array}$ \\
\hline
\end{tabular}

\subsection{Limited learning opportunities in primary care settings:}

Maintenance 'It depends on which GP you go to. Some of them you see for 5, 10 minutes max, and which is only just enough for them to look at you and go 'Yes this is what your problem is. Here's some drugs. Off you go', and there's no real-. You kind of can ask questions at some of them, but not really.' (ID79)

\subsection{Doubt about the credibility of my asthma diagnosis:}

Maintenance 'I never really thought about [having] asthma um because even in those moments it wasn't like really struggling for breath. And I had a friend who died... from asthma, so I know what his struggles were like and obviously mine were nothing even remotely close to what he had.' (ID63)

\subsection{Asthma knowledge deficits affect appropriate management:}

As-needed 'Yeah every year...I delay it until [my asthma's] really serious, then I go and see a doctor...'I don't see a doctor combination until I'm really, really dying or it affects my work, or I can't go to work'. (ID118)

As-needed 'There was that one night where I was coughing and coughing and I actually started getting concerned. I combination thought 'Well where is the point where I need to actually, you know, get help?'.' (ID64)

$\mathrm{RCT}$, randomised controlled trial. 
Table 4 How much effort this treatment regimen involves (theme 3 )

\begin{tabular}{|c|c|}
\hline RCT group & Quotation \\
\hline \multicolumn{2}{|c|}{ 4.1 Difficulty comprehending two different treatment approaches in the same regimen } \\
\hline Maintenance & $\begin{array}{l}\text { 'I have to consciously think 'Right this inhaler needs to be used that way' [taken twice a day], as } \\
\text { opposed to just having one [treatment approach] and thinking of one way of using it [take it as- } \\
\text { needed].' (ID102) }\end{array}$ \\
\hline \multicolumn{2}{|c|}{ 4.2 The preventer inhaler perceived to have comparatively little physical benefit } \\
\hline Maintenance & $\begin{array}{l}\text { 'Compared with a reliever there's no instant relief with the [preventer] so it's not something I think } \\
\text { about or remember to take... [it's] not as motivating [as Ventolin] but I feel like it's the main one that } \\
\text { I should be taking but I just don't feel as motivated because I don't feel the symptom relief from it.' } \\
\text { (ID50) }\end{array}$ \\
\hline \multicolumn{2}{|c|}{ 4.3 Difficulty establishing an effective ICS-taking routine } \\
\hline Maintenance & $\begin{array}{l}\text { 'Before the study I'd only ever taken um, the Ventolin whenever I needed it, so, like, that meant to } \\
\text { take that Pulmicort [inhaler] every day was more of a hassle than I was expecting... I mean taking it } \\
\text { everyday's like a hassle, so I just didn't.' (ID82) }\end{array}$ \\
\hline Maintenance & $\begin{array}{l}\text { 'It'll just be like 'Oh, I better do that'. And I would try to [take the preventer], and then you just kind } \\
\text { of get busy with lifestyles, and I don't know, that safety thing, I always knew that my Ventolin was in } \\
\text { my bag.' (ID11) }\end{array}$ \\
\hline Maintenance & $\begin{array}{l}\text { 'In the beginning [of the study] I was [taking the preventer] every morning, every night um and then } \\
\text { we went away overseas and it wasn't in my sight all the time so it was easier for me to forget.' } \\
\text { (ID63) }\end{array}$ \\
\hline \multicolumn{2}{|c|}{ 4.4 Forgetting ICS treatment when their symptoms were not apparent } \\
\hline Maintenance & $\begin{array}{l}\text { 'When I've been feeling really well, and not really thinking about my inhalers that makes me forget } \\
\text { to use them.' (ID102) }\end{array}$ \\
\hline
\end{tabular}

ICS, inhaled corticosteroids.

if the preventer inhaler was perceived to have comparatively little physical benefit this sometimes resulted in poor motivation for adherence:

...I feel like [the ICS inhaler's] the main one that I should be taking but I just don't feel as motivated because I don't feel the symptom relief from it. (ID50-Maint)

Barriers to taking the separate ICS inhaler were obviously reported only by those randomised to the 'Maintenance' regimen; these barriers included the burden or difficulty of establishing an effective ICS-taking routine (which could be worse at night, weekends, when travelling), or forgetting their preventer treatment when they did not perceive any symptoms:

When I've been feeling really well, and not really thinking about my inhalers that makes me forget to use them. (ID102-Maint).

Expanded quotes relating to theme 3 are found in table 4 .

My beliefs about the benefits and risks of this treatment (theme 4) Though many interviewees found their randomised treatment regimen effective (eg, perceiving longer relief, that is, feeling less wheezy, needing to use their reliever less), for others, in both RCT regimens, a lack of perceived benefit from adding a preventer medication to their previous SABA-only regimen, either via a second inhaler, or inside a single combined inhaler, limited its perceived effectiveness:

I didn't really see much of an improvement in my triggers like hiking, cold air, flu when I was taking it really regularly when I started the study....I don't do stuff just because I'm told it's good for me.... [so my use] just kind of dropped off ... (ID66-Maint).

Notably, some interviewees in the 'As-needed combination' group felt their study inhaler had less overall relief action or less speed of action compared with their previous SABA inhaler (as reported elsewhere ${ }^{10}$ ).

While a small number of interviewees in both groups had general concerns about the potential for treatment side effects prior to and/or when beginning the study regimen, some interviewees in the 'Maintenance' regimen group described a specific concern about corticosteroid-related weight gain;

I was a bit concerned because I believe [steroids], can make you put on weight...but because I take it in [nasal spray for hay fever] as well I was slightly concerned about that.

(ID84-Maint)

This concern was only raised by females, and they did not report it to have affected their study medication use.

The side effects patients described actually experiencing were largely similar between regimens, most 
Table 5 The benefits and risks of this treatment (theme 4)

RCT group Quotation

\subsection{Perceptions of regimen benefit}

\subsubsection{Regimen perceived as effective:}

$\begin{array}{ll}\text { Maintenance } & \text { 'It's just made me feel better in myself, knowing that I can do things more, 'cause I don't have to worry about } \\ & \text { 'Well I can't do this just in case I get asthma'.' (ID100) } \\ \begin{array}{ll}\text { As-needed } \\ \text { combination }\end{array} & \text { 'I'm really thrilled because I can see just how much better it works, how I feel afterwards and I can just carry } \\ & \text { on [Asthma's] not affecting me, you know, my life now...' (ID87) }\end{array}$

\subsubsection{Inability to perceive a benefit from adding a preventer medication:}

Maintenance 'I didn't really see much of an improvement in my triggers like hiking, cold air, flu when I was taking it really regularly when I started the study...I don't do stuff just because I'm told it's good for me, like I've got to feel like there's actually some benefit of it... [My use] just kind of dropped off... it just wasn't really feeling that there was any difference' (ID66)

\section{As-needed 'Every two, three weeks during winter, I have like asthma [symptoms], so I don't think that the maintenance combination type [medication works]... it quickly stops the asthma [symptoms] but it doesn't really stop the asthma [occurring again later].' (ID02)}

\subsubsection{As-needed combination inhaler had less overall relief action or less speed of action than past relievers:}

$\begin{array}{ll}\text { As-needed } & \text { 'I feel that compared to some other inhalers, it does take a little while to kick in as a reliever... whereas some } \\ \text { combination } & \text { other [reliever] inhalers I feel as soon as I take it I feel an instant relief... I'd probably say with my other ones it's } \\ & \begin{array}{l}\text { usually pretty instant, so within maybe } 30 \text { seconds, where the [study] one maybe takes a couple of minutes.' } \\ \text { (ID21) }\end{array}\end{array}$

\subsection{Perceptions of regimen risk}

\subsubsection{Concern about corticosteroid-related weight gain did not affect medication use:}

Maintenance 'I was a bit concerned because I believe [steroids], can make you put on weight. But I was told it wouldn't because it's only a tiny amount, but because I take it in [nasal spray for hay fever] as well I was slightly concerned about that' (ID84)

\subsubsection{Experience of oral thrush reduced the likelihood of future use:}

Maintenance 'I know that sometimes [oral thrush] gets too much and I'll just stop doing [my preventer] and I'm not gonna' lie and say that that's never, ever going to happen again... If I didn't get [oral thrush], I would be the most compliant patient in the world' (ID96)

$\mathrm{RCT}$, randomised controlled trial.

commonly unpleasant taste, and these also generally did not impact on RCT treatment implementation:

I just observe after I use [the study inhaler], like, numbing, my hands, like, shaking or sweating, something like that, a few minutes after taking... [but] it doesn't bother me.

(ID15-As-needed)

Oral thrush, only reported by one 'Maintenance' regimen patient who had past and RCT experiences of this side effect, significantly impacted on the likelihood of future use of maintenance ICS:

Sometimes [oral thrush] gets too much and I'll just stop doing [my preventer] and I'm not gonna lie and say that that's never, ever going to happen again (ID96-Maint)

Expanded quotes relating to theme 4 are found in table 5 .

\section{Personal preferences regarding future treatments for mild} asthma

Rationales for preferring a single combined inhaler

Interviewees reported their treatment preferences, and the associated rationales, for either a single combined preventer/reliever inhaler (taken as-needed) or separate preventer (taken twice daily) and reliever (taken as-needed) inhalers at the end of the interview. Most interviewees, within both RCT groups, preferred a single combined inhaler over separate reliever and preventer inhalers for their future treatment $(77 \%$ in 'As-needed'; $64 \%$ in 'Maintenance' group). Interviewees, within both RCT groups, considered a combined inhaler easier to manage (eg, one thing to remember to carry); as requiring less prescriptions and lower costs; and as providing a physical feeling of relief after use to motivate ongoing use that is missing with a separate ICS-only medication:

[What motivates me to take it is] to, to feel the effects, that relief and not only in that short-term but also in the longterm knowing that it'll be that much easier to walk up that hill.... (ID50-Maint).

Indeed, for one participant receiving the 'Maintenance' regimen, there was a firm caveat that any single combined inhaler must be as effective as two separate inhalers.

A rationale, which emerged only in relation to future treatment, was that a single combined inhaler could 
support preventer medicine use (through taking reliever doses of the combination inhaler), with the interviewee likening this to an adherence prompt:

\section{You'd remember to take it because obviously if it was relieving} the symptoms as well, that would help you to remember to take it... (ID84-Maint)

This echoes a treatment implementation challenge during the RCT described by patients in the "Maintenance' group (see Theme 3, above) of difficulty establishing an effective medication-taking routine with their separate ICS inhaler.

\section{Rationales for preferring separate reliever and preventer inhalers}

In contrast some interviewees in both RCT groups preferred separate reliever and preventer inhalers over a single combined inhaler for their future management. This preference was considerably more common among those allocated to the 'Maintenance' than the 'As-needed combination' regimen, and there were also clear differences in rationale by RCT group.

Only 'Maintenance' regimen interviewees felt that a combination inhaler may cause unnecessary use or overuse of preventer medication:

How would you know that you definitely need both [medications], if you're not taking them separately [first]?...I think I'm happy with the two separate ones, as it's what I am used to now...I like the option of possibly just needing one [reliever] inhaler and being able to separate that out. (ID102-Maint).

and/or that there could be increased side effects when taking a combination preventer-reliever as-needed, due to what they assumed would be greater corticosteroid exposure:

I think I would be concerned that if the only puffer I could take had that preventer medication in it, that it would worsen those side effects, if I needed to take it more often. (ID96-Maint)

Others felt that a combination inhaler may be insufficiently effective compared with the familiar SABA inhaler.

A rationale for separate inhalers, which emerged only in relation to future treatment preferences in both groups, was the familiarity/security of previously experienced treatment:

I'm not in an immediate rush to change. The course of medication I've been doing for my asthma for this past while I've been on the study I am happy with, so why risk that? (ID74-Maint)

Some 'Maintenance' group patients reasoned it was counterintuitive and detrimental to sustained use of their ICS to take a combination preventer medication as-needed in the future:
I don't think [an as-needed preventer] would work 'cause ... you'd be back into that ebb and flow thing, of you'd take it lots, lots, lots, feel good, stop taking it... (ID96-Maint)

In the 'As-needed combination' group, some interviewees cited effectiveness of salbutamol itself as a rationale for preferring separate reliever and preventer inhalers (or SABA therapy alone), reporting that they felt salbutamol worked faster for symptom relief or thought a salbutamol reliever may be a less strong medication than the combination medication (as reported elsewhere ${ }^{10}$ ).

Expanded quotes relating to rationales given by interviewees for preferring a single combined inhaler or separate preventer and reliever inhalers for future treatment are found in table 6 .

\section{DISCUSSION}

Our study reveals key patient perspectives on the factors motivating use of two different preventer treatments for mild asthma; these include: perceived asthma burden, disease knowledge, treatment complexity and treatment usefulness or safety. Such factors emerged in patients who had used either a maintenance or as-needed combination ICS-containing regimen for $\geq 10$ months prior to interview, but had previously used SABA-only treatment for the 3 months before study enrolment. ${ }^{3}$ Most interviewees tended to perceive their asthma as requiring little active care, and not inhibiting to their daily life, though it is uncertain if these perceptions were reliable given that asthma symptom habituation and difficulty distinguishing asthma symptoms from other causes (eg, anxiety) were also reported. The findings emphasise the importance of understanding patient perspectives in decision-making and education about new asthma treatments.

In our interviewees, there was generally limited knowledge about asthma, and a tendency to believe that their personal asthma risk was low. These patient perspectives are of obvious concern because, as in other research, ${ }^{16}$ they appeared to influence attitudes toward, and implementation of, prescribed preventer treatment. For example, the perception of low health risk from asthma combined with limited asthma knowledge meant that the necessity for an additional (ie, preventer) treatment was unclear especially when no direct physical benefit could be observed after using the ICS-containing inhaler. A recent qualitative study among patients predominantly prescribed maintenance ICS/long-acting beta2-agonist reported a lack of understanding about asthma as a barrier to self-management, and doubts about the necessity of ICS. ${ }^{16}$ The poor patient disease education in our interviewees with mild asthma may explain misconceptions about the (low) risk of their disease, a finding observed in studies of patients with more severe asthma. ${ }^{17}$ Education in mild asthma patients is urgently needed to increase understanding of the potential for severe exacerbations even in mild asthma, ${ }^{18} 19$ and the ability of ICS-containing treatment 
Table 6 Patient rationales ${ }^{\star}$ for their preferences regarding future treatment implementation

\section{RCT group Quotation}

6.1 Implementation preference: single combined inhaler

\subsubsection{Rationale-Easier to manage:}

$\begin{array}{ll}\text { Maintenance } & \begin{array}{l}\text { 'Obviously it's better to use only one inhaler if it does what both inhalers do. Because of convenience, } \\ \text { because, you know, you don't need to have two inhalers, chances are you will forget one of them when you } \\ \text { travel and yeah, just [a] convenience thing.' (ID65) }\end{array} \\ \begin{array}{l}\text { As-needed } \\ \text { combination }\end{array} & \text { 'It is much easier to all have it in one inhaler.... l'd rather have [an] all-in-one [than two separate inhalers].' }\end{array}$
combination (ID117)

\subsubsection{Rationale-Requiring less prescriptions and lower costs:}

Maintenance '[l'd] probably [choose] the one [inhaler that does both prevention and relief]. It's just less money [paying for one prescription].' (ID77).

As-needed 'Um, well being selfish the cost aspect [drives my preference for one inhaler] because obviously um, combination we have to pay for our medication and everything, and [the maintenance regimen'd] be classed as two medications so it'd be two costs, um, for me.' (ID59)

\subsubsection{Rationale-Providing a physical feeling of relief after use to motivate ongoing use:}

Maintenance 'What motivates me to take it is] to, to feel the effects. Like to feel that, that relief and not only in that shortterm but also in the long-term knowing that l'll be that much easier to walk up that hill, or things like that.' (ID50)

As-needed II struggled to take [a preventer inhaler in the past] because it wasn't obvious to me that it was working. Uh, combination you know a clear sign that it is working. Whereas when you take the reliever, it pretty much kicks in straight away, well from my experience'. (ID116)

\subsubsection{Rationale-Supports sustained ICS adherence:}

Maintenance ' [I would] definitely [choose] the one inhaler ... it would be easier to take, like, you'd remember to take it because obviously if it was relieving the symptoms as well, that would help you to remember to take it. It would be just be easier anyway just having the one to think about.' (ID84)

$\begin{array}{ll}\text { As-needed } & \text { "In the past] I set myself reminders on my phone to take [my preventer] and I'd still not take it. So the fact } \\ \text { combination } & \text { that I take it when I need it [is] um, very appealing to me. So, you know, I never forgot about taking it, um, } \\ & \text { [I] always had it on me.... I've quite enjoyed this as needed basis ((laughs)) so, yeah, it might be a challenge } \\ & \text { to have to go back to getting into that habit of yeah, routinely taking it, you know, at specific times a day'. } \\ & \text { (ID116) }\end{array}$

\subsubsection{Caveat-Any single combined inhaler must be as effective as two separate inhalers}

Maintenance 'My decision will be based on [the] therapeutic effect. If one inhaler will do the same as the blue one and white one, then yes [I would use it], but if it won't be the same I would stick with two different inhalers'. (ID65)

\subsection{Implementation preference: separate reliever and preventer inhalers}

\subsubsection{Rationale-The preventer inhaler may cause unnecessary overuse of ICS medication:}

Maintenance 'Because I very rarely need to use the Ventolin one, if I had a combined one I would feel that I would perhaps, be taking more medication than I needed... I think that maybe, putting chemicals in your body isn't a good idea. I mean there are some times where it has to happen...But ((laughs)), um, I certainly wouldn't put any chemicals in my body that I didn't need to'. (ID67)

\subsubsection{Rationale - The preventer inhaler may be insufficiently effective:}

Maintenance $\quad$ "if I felt that using a preventer assisted me a lot more I think I'd be more inclined to have [it]... But I think me personally no, I'd just stick with the blue [inhaler] because that's what, I guess what I know.' (ID62)

\subsubsection{Rationale-Increased side effects from as-needed preventer due to greater steroid exposure:}

Maintenance II think I would be concerned that if the only, the only puffer I could take had that preventer medication in it, that it would worsen those side effects, if I needed to take it more often. Whereas I like the fact that I know that it's only those two doses, and then anything on top of that I'm taking doesn't give me those side effects. So I mean I would be, I wouldn't like to have to take more than the two doses [of preventer medicine]'. (ID96)

\subsubsection{Rationale-Use of a daily preventer may interfere with stepping down to a reliever alone regimen:}

Maintenance 'How would you know that you definitely need both [medications], if you're not taking them separately [first]...I think I'm happy with the two separate ones, as it's what I am used to now...I like the option of possibly just needing one [reliever] inhaler and being able to separate that out.' (ID102) 
Table 6 Continued

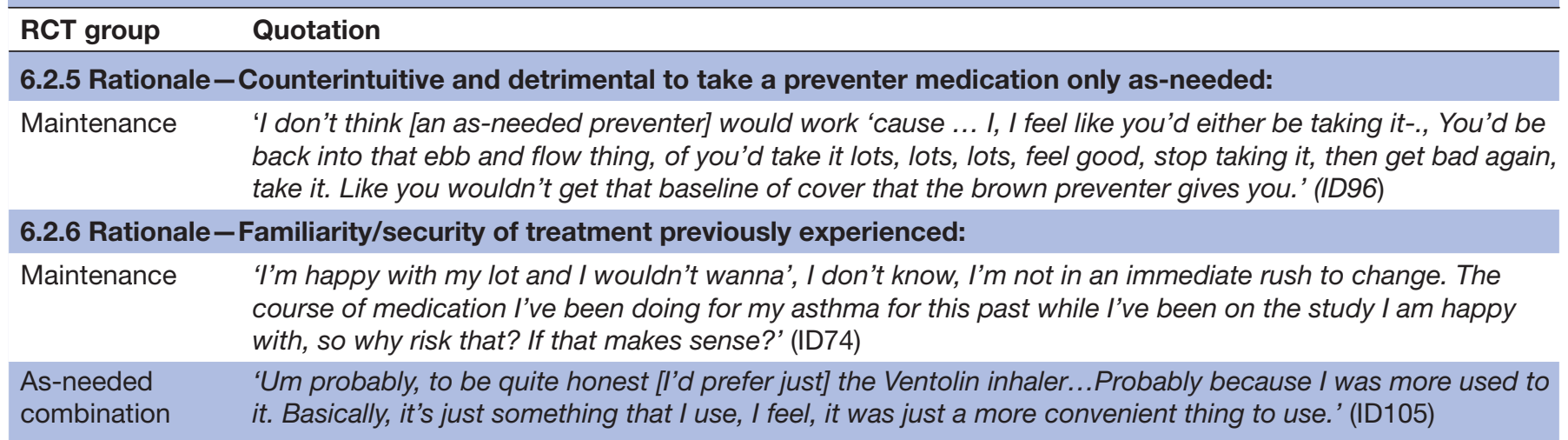

*Note: For a given rationale, if a quotation is tabulated for only one RCT group, that rationale only emerged in the single RCT group named. $\mathrm{RCT}$, randomised controlled trial.

to reduce these risks even if symptoms are periodic and/or appear mild and inconsequential. ${ }^{20} 21$ Patientcentred education can be provided not only by general practitioners and nurses, but also by pharmacists ${ }^{22}$; it should come not only from an academic medical/pharmacologic perspective, but also from an understanding of patients' lived experience of asthma. ${ }^{23}$

There were important differences in implementation behaviours between RCT regimen groups. Those randomised to the 'Maintenance' group reported greater difficulty implementing their regimen due to its greater complexity (adding a preventer inhaler to their previous SABA-only regimen), its higher cognitive demand (understanding the difference between two inhaled medications) and/or greater behavioural effort (taking one inhaler as-needed and another twice daily) compared with SABA alone. Obviously, this issue did not arise in the 'As-needed combination' group. A desire for convenient, simple treatments (easy to know when or how to take) has been reported in other asthma research. ${ }^{16}$ Indeed, those receiving the 'Maintenance' regimen reported a range of implementation problems with their daily preventer that that did not interfere with the 'As-needed combination' regimen, such as difficulty establishing an effective preventertaking routine or forgetting preventer treatment when symptoms were not present. Similarly, in the INSPIRE study, the proportion of patients underusing their maintenance medication was significantly higher when they felt well $(34 \%)$ compared with periods of worsening asthma $(18 \%){ }^{9}$

With respect to future treatment preferences, most patients randomised to either ICS-containing regimen in the NovelSTART RCT preferred the concept of a single combined inhaler (containing both a preventer and a reliever medication inside it) and taken as-needed, over separate reliever and preventer inhalers. In a quantitative survey at the end of the PRACTICAL study, ${ }^{6}$ $90 \%$ of those who had been randomised to as-needed budesonide-formoterol and $40 \%$ of those randomised to maintenance ICS said they would prefer an as-needed combination inhaler for their future treatment. ${ }^{24} \mathrm{In}$ the present interviews, patients receiving maintenance treatment who favoured as-needed combination treatment for the future (though they had not yet tried it) gave similar reasons for their preference as those who had used as-needed budesonide-formoterol in the RCT. These included: easy management (eg, one thing to remember); potential for lower prescription costs; and support for preventer adherence (eg, a single combined inhaler could provide a physical feeling of relief to motivate ongoing use). A recent study in asthma patients prescribed ICS reported a critical physiological/psychological motivation from feeling a tangible relief plus emotional reassurance from their reliever inhaler that was not felt with ICS-only inhalers. ${ }^{17}$

However, certain concerns about the single combined inhaler were reported. Some receiving the 'As-needed combination' regimen in the RCT felt that a single combined inhaler must always have an equivalent effectiveness for symptom relief as a SABA, and some preferred the familiarity/security of their past maintenance treatment. Those receiving the 'Maintenance' regimen in the RCT had additional issues such as difficulty grasping, or trusting in, the feasibility of a preventer medication taken as-needed and concerns around insufficient treatment benefit or unnecessary or overuse of preventer medication with the single combination inhaler. Attachment to previously used treatments, perceived lack of need for ICS when not experiencing symptoms, and concerns about ICS overuse have been reported in recent research with asthma patients prescribed maintenance ICS. ${ }^{16} 1725$ Similarly, in a recent discrete choice experiment (DCE) study ${ }^{26}$ of mild asthma patients at the end of the 12-month PRACTICAL RCT comparing as-needed combination treatment over maintenance therapy, ${ }^{6}$ the most important attributes for choosing an ICS regimen were prevention of shortness of breath and reduced risk for future flare ups. This mirrors our present findings regarding the importance of perceived 
effectiveness for treatment implementation. Regimen type was also important in the DCE study but only in those who preferred an as-needed regimen, though, as in this study, most patients overall (64\%) preferred as-needed combination over the maintenance regimen. ${ }^{26}$ While the present data suggest that the most easily implementable treatment for patients appears to be a single combined inhaler, patient concerns about this treatment approach must be addressed in order to ensure optimal implementation if this treatment is prescribed. Further, future research investigating the extent to which components of behavioural models (eg, the necessity-concerns framework) ${ }^{27}$ influence treatment preferences and impact patient care in mild asthma would be a very useful next step to enhance the literature on patient choices and acceptance of regimen options for mild asthma.

The use of qualitative methods, prospectively integrated into the design of the pragmatic clinical trial, is a major strength of this study allowing a less clinical and more patient-centred understanding on perspectives about new treatment options for patients with mild asthma. The fact that the rationales for ICS regimen preference provided by our interviewees were wider ranging than those described in previous mild asthma studies using survey-based or DCE methods ${ }^{24}{ }^{26}$ supports the need for this patient-centred qualitative study. Limitations include that interviewees were participants in a 12-month long RCT (which for those prescribed maintenance ICS may have increased their treatment adherence during the study) and had been receiving SABA-only treatment for at least 3 months prior to enrolment, and most had postschool education, thus limiting the generalisability of the results to patients in the general community, including those with very recently diagnosed asthma and/or new to asthma medications. A smaller proportion of RCT participants invited from the 'As-needed combination' group agreed to be interviewed, so those who consented to interview may have had a more positive view towards this treatment. Despite concerted efforts, we were unable to interview patients who had withdrawn from the RCT.

\section{CONCLUSIONS}

Our interviewees provided some of the first patientcentred guidance on factors to consider when introducing ICS-containing treatments now recommended by guidelines for patients with mild asthma. Common self-management challenges were described as factors affecting mild asthma treatment implementation. The concept of a single combined inhaler was the preferred future treatment option even among patients who had not yet tried it, due to its simplicity and similar usage patterns as those already acquired with SABA. However, other issues reported by interviewees make it clear that patient education is urgently needed to increase disease knowledge and to address implementation barriers when adding either type of preventer treatment in mild asthma.

Acknowledgements We warmly thank the participants in the study; NovelSTART clinical site staff for inviting their patients for NovelQ interviews, and Woolcock Institute staff Marilyn Yee, Khanh Huynh and Jesse Xu for assisting with recruiting patients, scheduling interviews and/or transcribing interviews.

Contributors JF: conceptualisation, methodology, formal analysis, investigation, writing-original draft. RB, IB, TH, MH and IP: contributed to conceptualisation, methodology, writing-review and editing. HR: conceptualisation, methodology, contributed to formal analysis, writing-review and editing, and is responsible for the overall content as guarantor for the work.

Funding This work was supported by an investigator-sponsored research grant from Astra Zeneca (ESR14/10452) and by Independent Research Organisation funding from Health Research Council of New Zealand (18/002). AstraZeneca was provided with a draft copy of the manuscript but had no involvement in the collection or analysis of the data, in the preparation of the manuscript, or in the decision to submit the manuscript for publication.

Competing interests JF reports independent research funding from AstraZeneca (AZ) and honoraria from AZ and Boehringer Ingelheim (BI) for independent medical educational presentations unrelated to this work. RB reports research funding from AZ, GlaxoSmithKline (GSK) and Genentech, and honoraria for consulting and/ or advisory boards from AstraZeneca, Cipla, Avillion and Theravance. TH reports research grants from $A Z$ and honoraria for advisory boards and speaker meetings from AZ and GSK. IP reports honoraria from AZ, BI, Aerocrine, Almirall, Novartis (Nov), GSK, Genentech, Regeneron, Teva, Chiesi, Sanofi,Circassia, Knopp. HKR reports advisory boards for AZ, BI, GSK, Nov, and Sanofi-Genzyme; consulting for AZ, GSK and Nov; honoraria from AZ, BI, GSK, Nov and Teva for independent medical educational presentations; and independent research funding from AZ, GSK and Nov. MH and IB have no conflicts of interest to declare in relation to this work.

Patient consent for publication Consent obtained directly from patient(s)

Ethics approval The study protocol was approved in Australia by the South Western Sydney Local Health District Human Research Ethics Committee (ref. HREC/15/LPOOL/554); in New Zealand by The Northern B Health and Disability Ethics Committee (ref: 15/NTB/96); and in the UK by the Health Research Authority (IRAS Project ID: 188191).

Provenance and peer review Not commissioned; externally peer reviewed.

Data availability statement Data are available on reasonable request. Access to deidentified transcripts from participant interviews will be available on reasonable request from 2 years after article publication, to researchers who provide a methodologically sound proposal for the purposes of achieving specific aims outlined in that proposal. Proposals should be directed to the chief investigator HR ( helen.reddel@sydney.edu.au). To gain access, data requesters will need to sign a data access agreement and to confirm that data will only be used for the agreed purpose for which access was granted.

Supplemental material This content has been supplied by the author(s). It has not been vetted by BMJ Publishing Group Limited (BMJ) and may not have been peer-reviewed. Any opinions or recommendations discussed are solely those of the author(s) and are not endorsed by BMJ. BMJ disclaims all liability and responsibility arising from any reliance placed on the content. Where the content includes any translated material, BMJ does not warrant the accuracy and reliability of the translations (including but not limited to local regulations, clinical guidelines, terminology, drug names and drug dosages), and is not responsible for any error and/or omissions arising from translation and adaptation or otherwise.

Open access This is an open access article distributed in accordance with the Creative Commons Attribution Non Commercial (CC BY-NC 4.0) license, which permits others to distribute, remix, adapt, build upon this work non-commercially, and license their derivative works on different terms, provided the original work is properly cited, appropriate credit is given, any changes made indicated, and the use is non-commercial. See: http://creativecommons.org/licenses/by-nc/4.0/.

\section{ORCID iDs}

Juliet Foster http://orcid.org/0000-0003-0780-6034 Richard Beasley http://orcid.org/0000-0003-0337-406X

Irene Braithwaite http://orcid.org/0000-0001-5327-3027

Tim Harrison http://orcid.org/0000-0002-3065-8247

Mark Holliday http://orcid.org/0000-0003-2344-6091

lan Pavord http://orcid.org/0000-0002-4288-5973 
Helen Reddel http://orcid.org/0000-0002-6695-6350

\section{REFERENCES}

1 Global Initiative for Asthma (GINA). Global strategy for asthma management and prevention 2021. Available: https://ginasthma.org/ reports/ [Accessed 28 June 2021].

2 Reddel HK, FitzGerald JM, Bateman ED, et al. GINA 2019: a fundamental change in asthma management: treatment of asthma with short-acting bronchodilators alone is no longer recommended for adults and adolescents. Eur Respir J 2019;53:1901046.

3 Beasley R, Holliday M, Reddel HK, et al. Controlled trial of budesonide-formoterol as needed for mild asthma. N Engl J Med 2019;380:2020-30.

4 O'Byrne PM, FitzGerald JM, Bateman ED, et al. Inhaled combined budesonide-formoterol as needed in mild asthma. $N$ Engl $J$ Med 2018;378:1865-76.

5 Bateman ED, Reddel HK, O'Byrne PM, et al. As-needed budesonideformoterol versus maintenance budesonide in mild asthma. $N$ Engl $J$ Med 2018:378:1877-87.

6 Hardy J, Baggott C, Fingleton J, et al. Budesonide-formoterol reliever therapy versus maintenance budesonide plus terbutaline reliever therapy in adults with mild to moderate asthma (practical): a 52-week, open-label, multicentre, superiority, randomised controlled trial. Lancet 2019;394:919-28.

7 Hatter LBP, Braithwaite I, Holliday M. ICS-formoterol reliever versus ICS and SABA reliever in asthma: a systematic review and metaanalysis. ERJ Open Research 2021;7:00701-2020.

8 Lycett H, Wildman E, Raebel EM, et al. Treatment perceptions in patients with asthma: synthesis of factors influencing adherence. Respir Med 2018;141:180-9.

9 Partridge MR, van der Molen T, Myrseth S-E, et al. Attitudes and actions of asthma patients on regular maintenance therapy: the INSPIRE study. BMC Pulm Med 2006;6:13.

10 Foster JM, Beasley R, Braithwaite I, et al. Patient experiences of asneeded budesonide-formoterol by Turbuhaler $\AA$ for treatment of mild asthma; a qualitative study. Respir Med 2020;175:106154.

11 Tong A, Sainsbury P, Craig J. Consolidated criteria for reporting qualitative research (COREQ): a 32-item checklist for interviews and focus groups. Int J Qual Health Care 2007;19:349-57.

12 Beasley R, Pavord I, Papi A, et al. Description of a randomised controlled trial of inhaled corticosteroid/fast-onset LABA reliever therapy in mild asthma. Eur Respir J 2016;47:981-4.

13 Miles MB, Huberman AM, Saldana J. Qualitative data analysis: a methods sourcebook. 3rd ed. Thousand Oaks: Sage, 2014.
14 Saldana J. The coding manual for qualitative researchers. 2nd ed. California: SAGE Publications, 2013.

15 Rodgers BL, Cowles KV. The qualitative research audit trail: a complex collection of documentation. Res Nurs Health 1993;16:219-26.

16 Baggott C, Chan A, Hurford S, et al. Patient preferences for asthma management: a qualitative study. BMJ Open 2020;10:e037491.

17 Blakeston S, Harper G, Zabala Mancebo J. Identifying the drivers of patients' reliance on short-acting $\beta 2$-agonists in asthma. Journal of Asthma 2021;58:1094-101.

18 Dusser D, Montani D, Chanez P, et al. Mild asthma: an expert review on epidemiology, clinical characteristics and treatment recommendations. Allergy 2007;62:591-604.

19 FitzGerald JM, Barnes PJ, Chipps BE, et al. The burden of exacerbations in mild asthma: a systematic review. ERJ Open Res 2020;6:00359-2019. doi:10.1183/23120541.00359-2019

20 Reddel HK, Busse WW, Pedersen S, et al. Should recommendations about starting inhaled corticosteroid treatment for mild asthma be based on symptom frequency: a post-hoc efficacy analysis of the START study. Lancet 2017;389:157-66.

21 Papi A, Braithwaite I, Ebmeier S, et al. Budesonide-formotero reliever therapy in intermittent versus mild persistent asthma. Eur Respir J 2021;57:2003064. doi:10.1183/13993003.03064-2020

22 Mes MA, Katzer CB, Wileman V, et al. Pharmacist-led adherence support in general practice: a qualitative interview study of adults with asthma. BMJ Open 2019;9:e032084.

23 Cheung MMY, Saini B, Smith L. 'It's a powerful message': a qualitative study of Australian healthcare professionals' perceptions of asthma through the medium of drawings. BMJ Open 2019;9:e027699.

24 Baggott C, Reddel HK, Hardy J, et al. Patient preferences for symptom-driven or regular preventer treatment in mild to moderate asthma: findings from the PRACTICAL study, a randomised clinical trial. Eur Respir J 2020;55:1902073. doi:10.1183/13993003.020732019

25 Foster JM, Smith L, Bosnic-Anticevich SZ, et al. Identifying patientspecific beliefs and behaviours for conversations about adherence in asthma. Intern Med J 2012;42:e136-44.

26 Baggott C, Hansen P, Hancox RJ, et al. What matters most to patients when choosing treatment for mild-moderate asthma? Results from a discrete choice experiment. Thorax 2020;75:842-8.

27 Horne R, Chapman SCE, Parham R, et al. Understanding patients' adherence-related beliefs about medicines prescribed for longterm conditions: a meta-analytic review of the Necessity-Concerns framework. PLoS One 2013;8:e80633. 